\title{
Risk Factors of Long-Term Care Insurance Certification in Japan: A Scoping Review
}

\author{
Shuko Takahashi ${ }^{1,2,3}$, Yuki Yonekura ${ }^{4}\left[\right.$, Nobuyuki Takanashi ${ }^{5}$ and Kozo Tanno ${ }^{5, * \mathbb{C}}$ \\ 1 Department of Health and Welfare, Iwate Prefectural Government, Morioka 020-8570, Iwate, Japan; \\ shutakahashi-iwt@umin.ac.jp \\ 2 Division of Medical Education, Iwate Medical University, Yahaba-cho 028-3694, Iwate, Japan \\ 3 Department of Critical Care, Disaster and General Medicine, Division of General Medicine, Iwate Medical \\ University, Morioka 020-8505, Iwate, Japan \\ 4 Department of Nursing Informatics, Graduate School of Nursing Science, St. Luke's International University, \\ Tokyo 104-0044, Japan; yyonekura@slcn.ac.jp \\ 5 Department of Hygiene and Preventive Medicine, School of Medicine, Iwate Medical University, \\ Yahaba-cho 028-3694, Iwate, Japan; pears_takanashi@ybb.ne.jp \\ * Correspondence: ktanno@iwate-med.ac.jp; Tel.: +81-19-651-5111 (ext. 5775)
}

Citation: Takahashi, S.; Yonekura, Y.; Takanashi, N.; Tanno, K. Risk Factors of Long-Term Care Insurance Certification in Japan: A Scoping Review. Int. J. Environ. Res. Public Health 2022, 19, 2162. https:// doi.org/10.3390/ijerph19042162

Academic Editors: Robbert Huijsman and Florian Fischer

Received: 27 December 2021

Accepted: 11 February 2022

Published: 14 February 2022

Publisher's Note: MDPI stays neutral with regard to jurisdictional claims in published maps and institutional affiliations.

Copyright: (C) 2022 by the authors. Licensee MDPI, Basel, Switzerland. This article is an open access article distributed under the terms and conditions of the Creative Commons Attribution (CC BY) license (https:// creativecommons.org/licenses/by/ $4.0 /)$.

\begin{abstract}
This study aimed to review evidence on future long-term care associated with pre-existing factors among community-dwelling Japanese older adults. We systematically searched cohort and nested case-control studies published between 2000 and 2019 that assessed long-term care certification using the PubMed, CINAHL, and EMBASE databases. The relationship between long-term care insurance information and risk factors was investigated. The protocol was registered with the Open Science Framework. We extracted 91 studies for synthesis, including 84 prospective cohort studies, 1 retrospective cohort study, and 6 nested case-control studies. Certification for long-term care was classified into two endpoints: onset of functional disability and dementia. There were 72 studies that used long-term care certification as a proxy for functional disability, and 22 used long-term care information to indicate the onset of dementia. Common risk factors related to functional disability were physical function, frailty, and oral condition. Motor function and nutritional status were common risk factors for dementia. We found consistent associations between premorbid risk factors and functional disability and dementia. The accumulation of evidence on the incidence of long-term care and associated factors can aid the development of preventive measures. Future studies should aim to integrate this evidence.
\end{abstract}

Keywords: dementia; functional disability; Japan; long-term care; longitudinal studies

\section{Introduction}

As the number of older adults increases worldwide, the number of functional disabilities experienced owing to comorbidities may also increase, along with dementia. The Organization for Economic Cooperation and Development member countries reported that 10 million people were affected by dementia in 2000, of which $7 \%$ were aged 65 or older [1]. The number of individuals with disabilities in the United States is estimated to reach approximately 21 million by 2040 [2]. In Japan, the rising number of older adults is projected to increase rates of functional disability [3,4] and dementia [5], raising serious concerns regarding the increasing care burden. The chronic care model is widely adopted worldwide to improve chronic patient outcomes by changing patients' care and managing chronic diseases [6,7]. Meanwhile, the government of Japan implemented the long-term care (LTC) insurance system in 2000, based on several European programs, to help older people with functional disabilities adequately manage their daily lives [8]. In 2017, about 6.4 million people received these certifications - a 2.5-fold increase over 17 years [9]—and LTC insurance expenditure reached JPY 9.4 trillion, from about JPY 4 trillion in 2000 [10]. Controlling 
the increase in the number of new LTC insurance certifications is an urgent health and financial challenge. It is necessary to determine the characteristics of people at risk of functional disability to establish effective preventive measures for functional disability.

To receive LTC certification, an older person first contacts the municipal government to apply for care needs. Trained local government officials then assess the individual's degree of functional disability using a questionnaire developed by the Ministry of Health, Labour and Welfare. Then, officials calculate the individual's standardized scores for physical and cognitive functions, based on the questionnaire, to determine whether the applicant is eligible for LTC insurance benefits. The Nursing Care Needs Certification Board decides whether an LTC insurance certificate should be issued, after considering the results of the initial assessment and using the primary care physician's statement and notes written by the assessor during a home visit. There are seven levels of care: Support Levels 1 and 2 (i.e., individuals who require daily assistance) and Care Need Levels 1 to 5 (i.e., individuals who are bedridden or in need of assistance for daily activities, such as eating and bathing). Once approved for LTC, they are eligible to take a monetary amount of services according to their level of functional disability and dementia.

Several studies have shown associations between recent LTC insurance certification as a proxy for functional disability and dementia and various risk factors, including physical and cognitive function, nutrition, laboratory findings, and social factors. However, a scientific review of risk factors for functional disability and dementia based on the LTC insurance system has not yet been conducted from the perspective of community-based studies. Therefore, we aimed to bridge this gap by systematically reviewing longitudinal studies concerning risk factors associated with LTC insurance certification in Japan.

\section{Materials and Methods}

\subsection{Protocol and Registration}

The review protocol was drafted according to the PRISMA Extension for Scoping Reviews (PRISMA-ScR) and reviewed by the authors. The final protocol was registered with the Open Science Framework and is available on the project page (https:/ / osf.io/5jyem/ (accessed on 29 June 2021)). The PRISMA-ScR checklist is provided in Appendix A.

\subsection{Study Inclusion Criteria}

Articles for this review were included if they met the following eligibility criteria: published between April 2000, when the Japanese LTC system started, and December 2019; written in English or Japanese; followed a prospective/retrospective cohort or nested case-control design to identify risk factors and estimate causality; the endpoint was LTC certification; participants were recruited from community settings.

\subsection{Literature Search}

The PubMed, CINAHL, and EMBASE databases were searched for studies published between April 2000 and December 2019. The final search strategy for PubMed is available in Appendix B.

\subsection{Data Selection}

Two authors (ST and KT) independently read the titles and abstracts of the identified studies to determine whether they should be included in this review. Studies were included when both authors agreed that these met the inclusion criteria. In cases of disagreement, a decision was made after a discussion between both authors (Figure 1). 


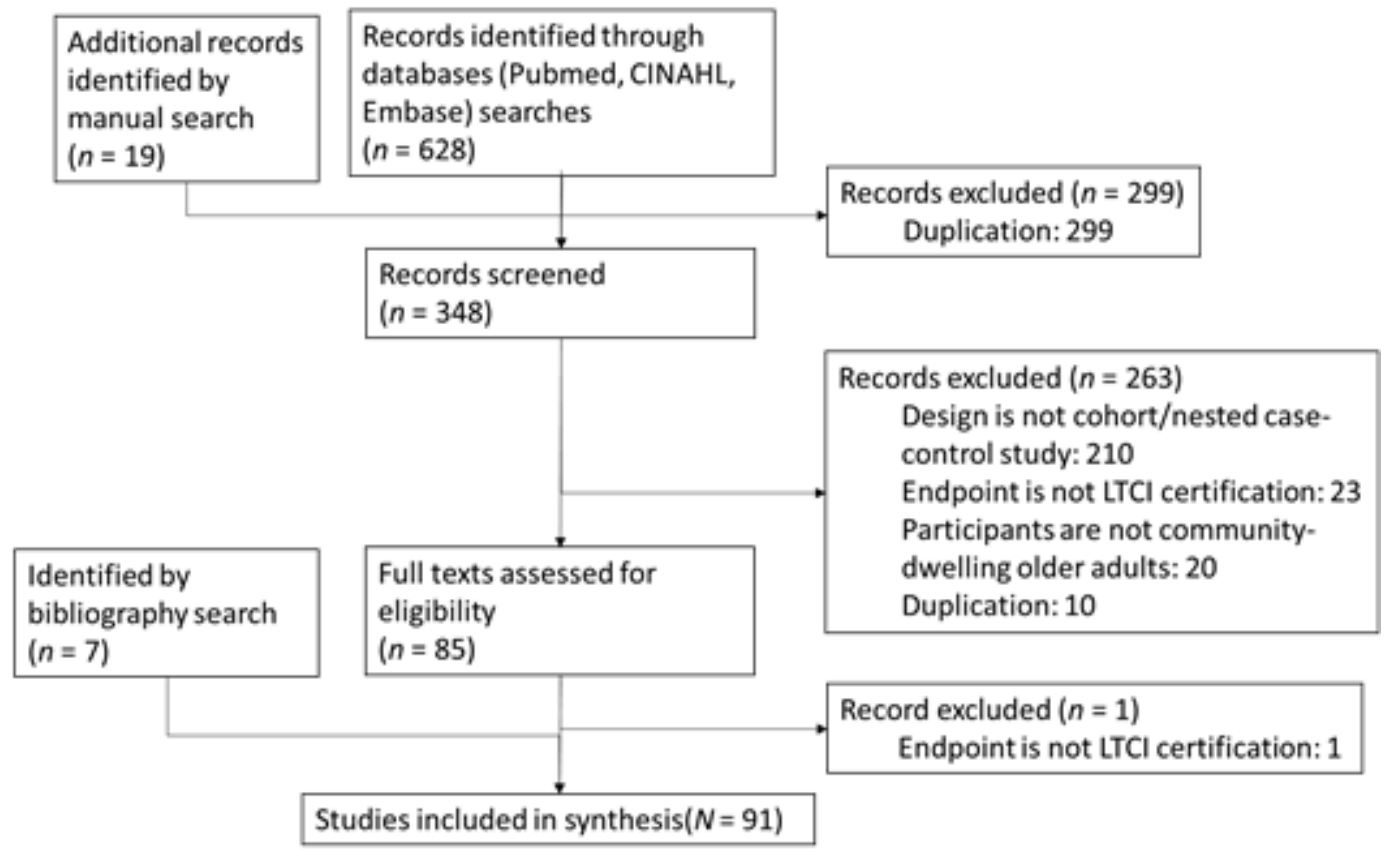

Figure 1. Flowchart of the literature review.

We identified 647 studies: 628 from the database search and 19 from the manual search. Of these, 299 studies were excluded because of duplication. After reading the titles and abstracts, 263 papers were excluded because they did not follow a cohort or nested case-control design $(n=210)$, the endpoint was not LTC certification $(n=23)$, study participants were not recruited from the community-dwelling population $(n=20)$, or they were duplicates $(n=10)$. Therefore, 85 papers were eligible for full-text review. Of these, one paper [11] was excluded from the analysis because its outcome was the trajectory of the Care Need Level. We examined the reference lists of the included studies to identify additional literature, and another seven articles were added. Ultimately, 91 studies were included in the analysis.

\subsection{Endpoints and Risk Factors}

Previously, LTC certification has been used as a proxy for the incidence of functional disability and/or dementia in studies. For this review, the endpoints of the reviewed studies were classified into two categories: functional disability and dementia. We investigated the levels of support and care provided by the LTC insurance system, the criteria for determining the onset of dementia, and the combined endpoint of LTC and death. Risk factors were categorized as physical condition, lifestyle, dental status, medical history, blood tests and clinical examinations, social factors, Kihon Checklist scores (a predictive tool for disability), and other.

\section{Results}

Of the 91 studies included in the analysis, 84 were prospective cohort studies, 1 was a retrospective cohort study, and 6 were nested case-control studies (Table S1). Seventy-two studies used LTC certification as an index of functional disability (Table 1). Levels of certification for LTC were highly prevalent: 64 studies focused on LTC Support Level $\geq 1$, 7 on LTC Care Need Level $\geq 2$, and 3 on Care Need Level $\geq 3$. Overall, 14 reports used LTC certification or death as the endpoint, and 22 used LTC certification as a proxy for the onset of dementia. Criteria for the onset of dementia were as follows: 20 studies referred to a degree of independence of II or higher among older adults with dementia, as determined by the accreditation, and 2 studies based disease classification on the attending physician's opinion. 
Table 1. Classification of endpoints in the reviewed articles.

\begin{tabular}{lcc}
\hline & $n$ & $\%$ \\
\hline Functional disability & 72 & \\
All Support/Care Need Levels & 64 & $88.9 \%$ \\
Above specific level & 10 & $13.9 \%$ \\
Care Need Level 2 & 7 & $9.7 \%$ \\
Care Need Level 3 & 3 & $4.2 \%$ \\
Composite endpoint with death & 12 & $16.7 \%$ \\
Analysis on cause of disability & 2 & $2.8 \%$ \\
Stroke & 2 & $2.8 \%$ \\
Joint & 2 & $2.8 \%$ \\
Other & 1 & $1.4 \%$ \\
Dementia & 22 & \\
Dementia scale rank II or above & 20 & $90.9 \%$ \\
Primary physician's comment & 2 & $9.1 \%$ \\
Composite endpoint with death & 2 & $9.1 \%$ \\
Analysis of cause of disability & 4 & $18.2 \%$ \\
Stroke & 4 & $18.2 \%$ \\
Joint & 0 & $0.0 \%$ \\
Other & 0 & $0.0 \%$ \\
\hline
\end{tabular}

Studies that employed both functional disability and dementia as outcomes were counted in each category.

Among the studies that considered LTC certification as a proxy for functional disability, the most common risk factor was physical condition (e.g., motor function, physical frailty, and sarcopenia; 15 studies), followed by medical history (14 studies), blood tests and clinical examinations (14 studies), and social factors (14 studies; Table 2). Among studies using LTC as a proxy for the onset of dementia, lifestyle factors such as diet and smoking were the most common risk factors (seven studies).

Table 2. Number of articles by combination of endpoint and risk factor.

\begin{tabular}{lccc}
\hline \multicolumn{1}{c}{ Risk Factor } & \multicolumn{2}{c}{ Endpoint } \\
\hline \multicolumn{1}{c}{ Category } & Functional Disability & Dementia & Total \\
\hline Physical condition & 15 & 3 & 17 \\
Motor function & 9 & 0 & 9 \\
Physical frailty and sarcopenia & 4 & 0 & 4 \\
Chewing ability & 3 & 0 & 3 \\
Leisure-time physical activity & 1 & 1 & 1 \\
Walking & 0 & 2 & 2 \\
Falls & 2 & 0 & 2 \\
Other physical function & 1 & 0 & 1 \\
Lifestyle & 6 & 7 & 13 \\
Smoking & 0 & 2 & 2 \\
Nutrition & 3 & 5 & 2 \\
Sleep & 1 & 1 & 2 \\
Combination of healthy lifestyle & 2 & 0 & 1 \\
behaviors & 1 & 0 & 8 \\
Other lifestyle factors & 7 & 1 & 18 \\
Dental status & 17 & 2 & 2 \\
Medical history & 2 & 0 & 2 \\
Hospitalization & 1 & 1 & 4 \\
Vascular diseases & 4 & 1 & 5 \\
Chronic kidney disease & 5 & 0 & 4 \\
Cognitive dysfunction & 4 & 0 & 1 \\
Psychological difficulties & 1 & 0 & 0 \\
Sensory organ abnormalities & 1 & 0 & \\
Pain & & & 2 \\
\hline
\end{tabular}


Table 2. Cont.

\begin{tabular}{lccc}
\hline \multicolumn{1}{c}{ Risk Factor } & \multicolumn{2}{c}{ Endpoint } \\
\hline \multicolumn{1}{c}{ Category } & Functional Disability & Dementia & Total \\
\hline Blood tests and clinical examinations & 12 & 4 & 15 \\
Blood tests & 7 & 3 & 10 \\
Clinical examinations (except blood & 2 & 0 & 2 \\
tests) & 3 & 1 & 3 \\
Body mass index & 13 & 3 & 16 \\
Social factors & 4 & 1 & 5 \\
Social participation, social support, & 4 & 0 & 4 \\
social capital, and social frailty & 2 & 0 & 2 \\
Social network & 1 & 1 & 2 \\
Living arrangements & 4 & 1 & 5 \\
Food availability & 6 & 0 & 6 \\
Other social factors & 1 & 1 & 2 \\
Kihon Checklist as a predictive tool for & disability & &
\end{tabular}

Studies that corresponded to multiple categories were counted in each category. Thus, the sum of categories does not match the total number of reviewed cases $(\mathrm{N}=91)$. Even if one study corresponded to multiple subcategories within the same category, the category count was counted as one case. Therefore, the sum of the subcategories does not match the frequency of the category.

\subsection{Physical Function}

Motor function was mainly measured objectively and included assessments of grip strength [12,13], knee extension torque [12], usual gait speed (6-m walk) [12], chair stand time [12], muscle dysfunction [12,14], the timed up and go (TUG) test [13], and one-leg standing time with eyes open [14].

Makino et al. showed that step count and moderate- to vigorous-intensity physical activity were associated with an increased disability risk [15]. Akune et al. reported that physical activities of daily living (ADLs) as assessed by the Western Ontario and McMaster Universities Osteoarthritis Index (WOMAC), a self-administered questionnaire used to measure patients' subjective function and pain status, were a predictor of functional disability [16]. Fujiwara et al. found that poor walking ability was associated with functional disability [17] and poor instrumental ADLs were associated with severe functional disability (Care Need Level $\geq 2$ ) [17]. Hirai et al. showed that daily walking time and frequency of going out were significantly associated with a higher incidence of functional disability [18]. Tsutsumimoto et al. demonstrated that slow gait speed and/or depression (assessed by the Geriatric Depression Scale (GDS)) were significantly associated with greater functional disability risk [19]. Hoshi et al. showed that the predictive power of physical function, assessed using the Motor Fitness Scale questionnaire, was equivalent to that assessed using physical performance measures, such as maximum walking velocity, the TUG test, leg extension power, and the functional reach test [20].

Chen et al. suggested that prefrail and frail individuals, measured by two frailty criteria from the Cardiovascular Health Study and a simple frailty questionnaire (FRAIL), had a significantly higher risk of functional disability [21]. Makizako et al. [22] and Shimada et al. [23] focused on the various components of frailty. Some components, such as slowness, weakness, and weight loss, were strongly associated with future disability [22], while prefrailty with slow walking speed and frailty with and without slow walking speed were associated with a higher risk of disability [23].

Regarding sarcopenia, Tanaka examined the validity of the "Yubi-wakka" (finger-ring) test for the swift assessment of sarcopenia as a practical method to identify severe functional disability (Care Need Level $\geq 3$ ) [24]. Participants whose calf circumference was smaller than their finger-ring circumference had increased disability risk [24].

Fujiwara reported that poor chewing ability was predictive of functional disability only in women [17]. Hirai et al. showed a substantial association between biting ability and 
functional disability, regardless of sex [18]. Moriya et al. demonstrated that participants aged 65-79 years with fair or poor masticatory ability had a significantly higher risk of functional disability than those with good masticatory ability [25].

Based on a questionnaire and incidence of functional disability, Matsunaga et al. found no significant association between the amount of leisure-time physical activity and functional disability but did show an inverse dose-response relationship between the amount of leisure-time physical activity and incidence of dementia in men [26].

Tomata et al. examined the association between changes in time spent walking and incidence of disabling dementia [27]. People who spent at least $1 \mathrm{~h}$ walking per day had a lower risk of dementia than those who spent less than 30 min walking per day. Additionally, the population attributable fraction (PAF) for dementia was $18.1 \%$ if all participants spent at least $1 \mathrm{~h}$ walking per day and $14.0 \%$ if participants increased their daily walking time by one level [28].

Hirai et al. indicated that falling in the past year was significantly associated with functional disability in both sexes [18]. Makino et al. showed that those with a fear of falling, either with or without a fall history, had a higher incidence of functional disability than those with neither a fear of falling nor a fall history [29].

Hirai et al. demonstrated an association between excretion impairment and a higher risk of functional disability in both sexes [18].

\subsection{Lifestyle Factors}

Ikeda et al. revealed an association between smoking and dementia [30], where current smokers were at twice the risk of dementia compared with those who had never smoked. Noguchi-Shinobara et al. clarified that current smokers with diabetes were at a greater risk of dementia than never smokers without diabetes [31].

In the Ohsaki Cohort Study, green tea consumption was associated with a lower risk of functional disability [32]. Furthermore, in an analysis combining the data sets from the Ohsaki Cohort Study and Ohsaki Cohort 2006, Matsuyama et al. and Tomata et al. showed that improved adherence to the Japanese diet was associated with a lower risk of functional disability, regardless of initial adherence status [33,34]. Japanese dietary patterns, citrus consumption, mushroom consumption, and coffee consumption were all shown to be associated with a lower risk of dementia [35-39].

Lu et al. showed that individuals with long sleep duration had a higher incidence of dementia [40]. Zhang et al. revealed that shorter sleep duration ( $<6 \mathrm{~h} /$ day) was associated with a higher risk of functional disability when considering death as a competing event [41].

Zhang et al. examined the effect of a combination of healthy lifestyle behaviors, including smoking status, time spent walking, and consumption of fruit and vegetables [42,43]. Their findings showed that adherence to each additional healthy lifestyle behavior resulted in a PAF of $10.5 \%$ for disability reduction [42]. They also showed that those who adhered to all three healthy lifestyle behaviors lived an average of 17.1 months longer without functional disability [43].

Yagi et al. showed that a high frequency of bathing ( $\geq 7$ times/week) was associated with a lower risk of functional disability compared to a low frequency of bathing ( 0 to 2 times/week) [44].

\subsection{Dental Condition}

Aida et al. showed that respondents with $\leq 19$ teeth had a higher risk of functional disability than those with $\geq 20$ teeth [45]. Komiyama et al. reported that participants without regular dental appointments had a significantly higher incidence of functional disability than those with regular dental appointments [46]. They also showed that participants with 10-19 teeth, 1-9 teeth, or no teeth were more likely to develop functional disability than those with $\geq 20$ teeth [47]. They assessed dentition status using Miyachi's Triangular Classification and showed that patients with 10 remaining teeth and patients with 4 occlusal supports and 11 remaining teeth were more likely to develop functional disability 3 or more 
years after the baseline survey [48]. Ohi et al. found that a lower maximum occlusal force was significantly associated with an increased risk of functional disability [49]. Bando et al. revealed that frequent toothbrushing decreased the incidence of functional disability [50]. Yamamoto et al. demonstrated that the risk of dementia onset was significantly higher in those with few teeth and without dentures and those who did not have regular dental checkups, compared to others [51].

\subsection{Medical History}

Hirai et al. noted that currently being treated for a disease represented a risk factor for functional disability [18]. However, Fujiwara found that history of hospitalization during the past year was predictive of functional disability only in women [17].

Nitta et al. showed that participants with peripheral arterial disease, especially those with low physical function, had a higher risk of functional disability [52]. Jinnouchi et al. showed that retinal vascular changes, such as generalized arteriolar narrowing and two or more retinal abnormalities, were associated with an increased risk of dementia [53].

Yamada et al. demonstrated that participants with an estimated glomerular filtration rate $(\mathrm{eGFR})<60.0 \mathrm{~mL} / \mathrm{min} / 1.73 \mathrm{~m}^{2}$ had an elevated risk of functional disability [54]. Lee et al. showed that lower eGFR was a risk factor for functional disability among those who had $\geq 8$ h of sedentary time per day [55]. Himeno et al. showed that chronic kidney disease (CKD) patients with moderate systolic blood pressure (130-159 $\mathrm{mmHg}$ ) were at a lower risk of functional disability and dementia compared to those with low systolic blood pressure $(<130 \mathrm{mmHg})$; however, these relationships were not found in non-CKD patients [56]. Watanabe et al. showed that CKD, diabetes, and lower HbA1c comorbidity was a strong predictor of functional disability [57].

Nishiguchi et al. demonstrated that cognitive decline, as evaluated by the Cognitive Performance Scale, was associated with an increased risk of functional disability [58]. Taniguchi et al. demonstrated a dose-response relationship between changes in MiniMental State Examination score per year and incidence of severe functional disability (Care Need Level $\geq 2$ ) [59]. Fujiwara et al. showed that severe cognitive decline was a predictor of severe functional disability (Care Need Level $\geq 2$ ) only in men [17]. Makizako et al. showed that cognitive function and depressive symptoms were associated with functional disability incidence [22]. Shimada et al. showed that psychological frailty, defined as the copresence of physical frailty and depressive mood (GDS-15), was associated with a higher risk of functional disability [60].

Four papers focused on psychological factors associated with functional disability. Tomata et al. [61] demonstrated a dose-response relationship between psychological distress, measured by $\mathrm{K} 6$ scores, and incidence of functional disability. Yamazaki et al. and Ohmori-Matsuda et al. showed that a depressive state, as assessed by the GDS, was a risk factor for functional disability [62,63]. Hirai et al. revealed a sex difference in terms of severe functional disability (Care Need Level $\geq 2$ ) and depressive state as assessed by the GDS [18].

Bae et al. showed that hearing problems and a lack of social activity were independent risk factors for developing functional disability [64]. Hirari et al. found that, while visual impairment was significantly related to the incidence of severe functional disability in men (Care Need Level $\geq 2$ ), hearing problems were related to severe functional disability in women [18].

Makino et al. demonstrated that severe pain was associated with a higher risk of functional disability than mild pain [65].

\subsection{Blood Tests and Clinical Examinations}

The Tsurugaya Project reported relationships between blood test data and functional disability in five studies. The first study identified an inverse linear relationship between serum albumin levels and functional disability or death [66]. The second study on plasma NT-pro BNP levels showed that participants in the 90 th percentile $(241 \mathrm{pg} / \mathrm{mL})$ or with 
higher plasma NT-pro BNP levels had a significantly higher risk of functional disability or death than those in the 25th percentile [67]. The third study showed that the relationship between adiponectin and the composite outcome of incident disability and death was partly explained by reduced physical function and wasting in participants with higher adiponectin levels $(\geq 22.4 \mathrm{mg} / \mathrm{L})$ [68]. The fourth study showed that higher equol levels $(\geq 23.6 \mathrm{ng} / \mathrm{mL})$, but not any other isoflavones, were inversely associated with an increased risk of functional disability or death [69]. The fifth study showed that lower levels of serum total cholesterol $(<177 \mathrm{mg} / \mathrm{dL})$ were significantly associated with an increased risk for functional disability, compared with 212-230 mg/dL [70].

The Circulatory Risk in Communities Study (CIRCS) conducted three studies on the association between blood markers and dementia. The first showed that serum coenzyme Q10 levels were inversely associated with the risk of dementia [71]. The second showed that elevated high-sensitivity C-reactive protein levels were associated with increased risk of dementia in individuals with a history of stroke, but not in those without [72]. The third showed that serum alpha-linolenic acid levels were inversely associated with the risk of dementia [73].

In another study on blood markers, Doi et al. found that lower serum IGF-1 levels were significantly associated with an increased risk of functional disability [74]. Further, Yamazaki et al. demonstrated that low ALT (<20 IU/L) was significantly associated with an increased risk of functional disability (Care Need Level $\geq 2$ ) or death [75].

Takahashi et al. showed that urine albumin-creatinine ratio was a predictor for incidence of functional disability, even after adjusting for the onset of cardiovascular disease during the follow-up period [76]. Okuno et al. showed that subclinical major electrocardiographic abnormality predicted a higher risk of functional disability among older adults with no prior history of cardiovascular disease [77].

Although the cut-off values differed among studies, being underweight was identified as a risk factor for functional disability. Honda et al. showed that the young-old (65-74 years) with a body mass index (BMI) $<18.5 \mathrm{~kg} / \mathrm{m}^{2}$ had a higher risk of functional disability compared to those with a BMI of 18.5 to $<25.0 \mathrm{~kg} / \mathrm{m}^{2}$ [78]. Zhang et al. showed that a BMI $<23 \mathrm{~kg} / \mathrm{m}^{2}$ was a risk factor for functional disability due to dementia and a $\mathrm{BMI} \geq 29 \mathrm{~kg} / \mathrm{m}^{2}$ was a risk factor for functional disability due to joint disease [79]. Using 10-year follow-up data from the same cohort, they also showed that disability-free survival was 7.8 to 25.6 months shorter in those with a BMI $<23$ or $\geq 29 \mathrm{~kg} / \mathrm{m}^{2}$, compared with $25-27 \mathrm{~kg} / \mathrm{m}^{2}[80]$.

\subsection{Social Factors}

Hirai et al. showed a significant association between participation in group activities and functional disability [18]. Ashida et al. demonstrated those who participated in a sports or hobby group, or who were group facilitators, were less likely to develop a disability, and the associations were stronger among highly educated older adults [81]. Otsuka et al. indicated that cognitive activity and time spent walking modified the association between social participation and incident functional disability [82].

Nemoto et al. showed that those who participated in social activities had a significantly lower risk of dementia than those who did not, among both the young-old and oldold [83]. In addition, this study demonstrated that those holding leadership positions had a significantly lower risk of dementia than regular members [83]. Saito et al. demonstrated that participating in community groups (e.g., sports groups) or engaging in paid work was significantly associated with decreased dementia risk [84].

Hirai et al. assessed receiving and providing emotional and instrumental support as social support, and frequency of contact with friends and going out as social characteristics [18]. Yokokawa et al. demonstrated that being homebound, operationally defined as walking outdoors for $<5 \mathrm{~min} /$ day, was a risk factor for functional disability in women but not in men [85]. Makizako et al. demonstrated that social frailty, assessed using simple questions regarding living alone, frequency of going out compared with the previous year, 
visiting friends, feeling helpful to friends or family, and talking with someone every day, was associated with an increased risk of functional disability [86]. Saito et al. showed that social relationship diversity scores (range: 0 to 5) using social relationship domains (social support, social networks, and social activities) had an inverse linear relationship with dementia incidence [84]. Noguchi et al. showed that higher levels of community social cohesion reduced the risk of functional disability (Care Need Level $\geq 2$ ) in men but not in women [87].

Saito et al. showed that older adults living only with their children had a significantly higher risk of functional disability than those living in three-generation households [88]. Saito et al. showed that men with nonspousal cohabitants and those living alone had a higher risk of functional disability than those living with a spouse, whereas there were no significant associations in women [89].

Momosaki et al. showed that low subjective food store availability was associated with a high risk for functional disability [90]. Tani et al. also reported that lower objective and subjective food store availability was associated with a high risk of dementia [91].

Hirai et al. showed that education $\leq 9$ years was associated with an increased risk of functional disability in men, but not in women [18]. Takasugi et al. demonstrated that people of both sexes with $<6$ years of education had a higher risk of dementia than those with $\geq 13$ years of education. In women, but not in men, there was an association between equivalized household income and dementia risk [92]. Nurrika et al. showed that a higher educational level (upper secondary education and above) was negatively associated with the incidence of functional disability. Participation in community activities contributed moderately to the relationship between education level and functional disability in those aged 65-74 years [93].

Kondo et al. indicated an association between relative deprivation, calculated using the Yitzhaki Index, and functional disability in men but not women. In addition, men with higher incomes may be more vulnerable to relative deprivation than those with lower incomes [94]. Kondo et al. demonstrated that the intensity and attitude domain of Mujin, Japanese rotating savings and credit associations, was associated with a low risk of functional disability (Care Need Level $\geq 3$ ), whereas the financial domain of Mujin had negative effects on incident disability [95].

\subsection{The Kihon Checklist as a Predictive Tool for Disability}

The KCL consists of 25 items categorized into seven structured domains: "20 items other than five related to depressive mood domain", "physical functions", "nutritional state", "oral function", "homebound state", "cognitive function", and "depressive mood". Tomata et al. demonstrated that all domains of the KCL were associated with the risk of 1-year incidence of functional disability [96]. Kamegaya et al. showed a higher risk of 3-year incidence of functional disability in four domains: "physical function", "nutritional state", "cognitive function", and "depressive mood" [97]. Okabe et al. showed that the KCL predicted health life expectancy better (Care Need Level $\geq 2$ or death) than the items related to specific health checkups, such as urine protein [98]. Satake et al. found that KCL classification of physical frailty status could be a significant tool to predict the 3-year risk of functional disability [99]. Katsura et al. showed that many, but not all, items were significantly associated with a 5-year risk of functional disability among both the young-old and old-old [100]. Shinkai et al. validated the checklist against the original version for screening high-risk older adults [101].

\subsection{Other}

Hirai et al. demonstrated that instrumental self-maintenance, effectance, and social role, as assessed by the Tokyo Metropolitan Institute of Gerontology Index of Competence (TMIG-IC), were associated with the incidence of functional disability in both sexes [18].

Kotaki et al. examined the joint impact of seven risk factors: diabetes mellitus, hypertension, obesity, physical inactivity, severe psychological distress, smoking, low educational 
attainment, and dementia. They found a dose-response relationship between the total number of risk factors and incident dementia and that participants had improved toward a better category, PAF $23.0 \%$ [102].

\section{Discussion}

Different endpoints of functional disability were assigned in each study, such as LTC Support Level $\geq 1$ or LTC Care Need Level $\geq 2$. Previous studies have shown that LTC certification level is closely related to ADL performance [103]. LTC Care Need Level 2 was defined as the requirement of assistance in at least one basic ADL task [50]. Some studies defined individuals with LTC Care Need Level $\geq 3$ as having severe functional disability, while others used LTC Care Need Level $\geq 2$ as an indicator of functional disability. Since each level of LTC insurance differs for physical disability and cognitive function, further studies are needed to definitively determine severe functional disability.

Twenty articles used a rank of II or higher on the dementia scale in primary doctors' opinion papers for the onset of dementia. This cut-off point is consistent with the cut-off evaluated by the gold standard in Meguro et al. [5] and Noda et al. [104]. However, although information on LTC can be used as an index for dementia onset, one limitation might be that actual causes of dementia, such as cerebrovascular disease, could not be determined.

Overall, motor function has been reported to be consistently associated with incident functional disability and dementia through objective and subjective measurements. However, the actual amount of physical activity and daily exercise level, along with changes in activity, have not yet been fully evaluated. Physical frailty, prefrailty, and social frailty, including KCL items, were well investigated in the analyzed articles. Combining physical and social frailty may bolster the effectiveness of preventive measures prior to LTC certification.

In most studies, modifiable risk factors, such as drinking, smoking, obesity, being underweight, nutrition, and physical activity were analyzed as covariates. More detailed analyses of smoking and drinking behaviors might support growing evidence for LTC (e.g., the number of cigarettes smoked or smoking cessation). The presence or incidence of disease is a mediating factor between lifestyle factors and LTC. Adjusting for these diseases sequentially may help to identify major factors associated with LTC. Blood tests and clinical examinations may be used as screening tools to estimate future LTC needs. Although social factors have been examined, stratified analyses should be considered to identify vulnerable groups.

Some articles indicated sex differences in risk factors for future LTC. For example, the relationship between depressive states and functional disability was significant only in men in the study of Ohmori-Matsuda et al. [63]. Investigating sex differences between risk factors and LTC may provide insight into sex differences in longevity. Furthermore, risk groups could potentially be identified by combining several risk factors with conventional risk factors $[42,43]$.

Most studies in this review were conducted among individuals aged 65 or older. Several studies indicate that lifestyles in midlife contribute to a decline in activities of daily living and cognitive function in later life [105-107]; however, few studies have summarized the association with LTC insurance certification. Thus, the association between lifestyle factors, blood tests, clinical examinations, and LTC among middle-aged people remains unclear. In terms of LTC prevention, life-course approaches are needed to clarify the midlife risks of LTC insurance certification to predict their later life. Consequently, interventions and cohort studies with long-term follow-up are needed among middle-aged people.

The main purpose of this study was to provide an overview of the status of longitudinal observational studies using endpoints related to LTC certification. Thus, studies that employed changes or trajectories of levels in LTC as outcomes were not included in this review. Since LTC assessment was correlated with functional disability and cognitive function in previous studies [94,103], an assessment of LTC allows us to evaluate patients' general status of physical and cognitive disabilities on a scientific basis. In addition, all candidates who have a functional disability and/or dementia and seek to apply for services 
must be assessed by officials in the local government in Japan. Given that policymakers can verify the effect implemented, LTC is applicable for evaluating cost and effectiveness as a health care policy. Global policymakers should consider these risk factors when seeking to implement effective preventive measures against functional disability and intervene sooner.

LTC insurances are provided by the Government of Japan to disabled elderly, including those with physical disabilities and those with cognitive dysfunctions. Meanwhile, several care models are applied to the elderly worldwide. For example, the chronic care model is widely used to improve chronic patient outcomes by changing patients' care and managing chronic diseases [6]. The chronic care model is compatible with LTC insurance in terms of availability to take care and services, particularly for functional disability, as one of the major endpoints of LTC in the present review. Therefore, the results in the endpoints of LTC could be interpreted in the international context by partially predicting those who need support in the chronic care model.

This review has some limitations. First, the variation in methods for exposure measurement was not examined. Furthermore, we did not verify the validity of the instruments or assess the quality of the included studies. Second, the magnitude of factors associated with LTC could not be elucidated. Accumulating studies through meta-analyses might help to understand the differences in magnitude among the risk factors. In Japan, to prevent frailty and sarcopenia, the Ministry of Health, Labour and Welfare promoted the integration of LTC prevention services with health care strategies in April 2020 [108]. The project recommends using a 15-item questionnaire (including general health perception; life satisfaction; and physical, cognitive, mental, social, and oral frailty) to evaluate health conditions and identify frail persons among older people. Despite these limitations, to the best of our knowledge, there has been no scientific review of risk factors for the LTC insurance system in Japan. Furthermore, we showed two different endpoints regarding functional disability and dementia, which might provide important findings regarding the effectiveness of implementing modifiable risk factors for either functional disability or dementia. Therefore, we believe that this review concerning risk factors of LTC insurance certification has helped to clarify the scientific evidence for promoting the project.

\section{Conclusions}

We conducted a scoping review of the association between various risk factors and LTC insurance certification as a proxy for functional disability and dementia. Although risk factors such as motor function and frailty were assessed in most reports, these mechanisms were not fully investigated. Further studies should work toward developing preventive measures for functional disability.

Supplementary Materials: The following supporting information can be downloaded at: https: / / www.mdpi.com/article/10.3390/ijerph19042162/s1, Table S1: Summary of study characteristics and findings.

Author Contributions: Conceptualization, K.T.; methodology, S.T., Y.Y. and K.T.; investigation, S.T., Y.Y., K.T. and N.T.; data curation, Y.Y.; writing—original draft preparation, S.T. and Y.Y.; writingreview and editing, K.T. and N.T.; project administration, S.T. and K.T.; funding acquisition, S.T. and K.T. All authors have read and agreed to the published version of the manuscript.

Funding: This study was conducted with the support of the Takemi Program in International Health at the Harvard T.H. Chan School of Public Health, and JSPS KAKENHI Grant Number JP20K18858 and JP21K10477.

Institutional Review Board Statement: Not applicable.

Informed Consent Statement: Not applicable.

Conflicts of Interest: The authors declare no conflict of interest. 


\section{Appendix A. Preferred Reporting Items for Systematic Reviews and Meta-Analyses Extension for Scoping Reviews (PRISMA-ScR) Checklist}

\begin{tabular}{|c|c|c|c|}
\hline SECTION & ITEM & PRISMA-ScR CHECKLIST ITEM & $\begin{array}{l}\text { REPORTED } \\
\text { ON PAGE \# }\end{array}$ \\
\hline \multicolumn{4}{|l|}{ TITLE } \\
\hline Title & 1 & Identify the report as a scoping review. & 1 \\
\hline \multicolumn{4}{|c|}{ ABSTRACT } \\
\hline $\begin{array}{l}\text { Structured } \\
\text { summary }\end{array}$ & 2 & $\begin{array}{l}\text { Provide a structured summary that includes (as applicable): background, } \\
\text { objectives, eligibility criteria, sources of evidence, charting methods, results, } \\
\text { and conclusions that relate to the review questions and objectives. }\end{array}$ & 1 \\
\hline
\end{tabular}

\section{INTRODUCTION}

Rationale

3

Describe the rationale for the review in the context of what is already known. review approach.

Provide an explicit statement of the questions and objectives being

Objectives 4 addressed with reference to their key elements (e.g., population or
participants, concepts, and context) or other relevant key elements used to conceptualize the review questions and/or objectives.

\begin{tabular}{|c|c|c|c|}
\hline \multicolumn{4}{|l|}{ METHODS } \\
\hline $\begin{array}{l}\text { Protocol and } \\
\text { registration }\end{array}$ & 5 & $\begin{array}{l}\text { Indicate whether a review protocol exists; state if and where it can be } \\
\text { accessed (e.g., a Web address); and if available, provide registration } \\
\text { information, including the registration number. }\end{array}$ & 2 \\
\hline Eligibility criteria & 6 & $\begin{array}{l}\text { Specify characteristics of the sources of evidence used as eligibility criteria } \\
\text { (e.g., years considered, language, and publication status), and provide a } \\
\text { rationale. }\end{array}$ & 2 \\
\hline $\begin{array}{l}\text { Information } \\
\text { sources * }\end{array}$ & 7 & $\begin{array}{l}\text { Describe all information sources in the search (e.g., databases with dates of } \\
\text { coverage and contact with authors to identify additional sources), as well as } \\
\text { the date the most recent search was executed. }\end{array}$ & $2-3$ \\
\hline Search & 8 & $\begin{array}{l}\text { Present the full electronic search strategy for at least } 1 \text { database, including } \\
\text { any limits used, such that it could be repeated. }\end{array}$ & Appendix B \\
\hline $\begin{array}{l}\text { Selection of } \\
\text { sources of } \\
\text { evidence }+\end{array}$ & 9 & $\begin{array}{l}\text { State the process for selecting sources of evidence (i.e., screening and } \\
\text { eligibility) included in the scoping review. }\end{array}$ & 3 \\
\hline $\begin{array}{l}\text { Data charting } \\
\text { process } \ddagger\end{array}$ & 10 & $\begin{array}{l}\text { Describe the methods of charting data from the included sources of evidence } \\
\text { (e.g., calibrated forms or forms that have been tested by the team before their } \\
\text { use, and whether data charting was done independently or in duplicate) and } \\
\text { any processes for obtaining and confirming data from investigators. }\end{array}$ & Figure 1 \\
\hline Data items & 11 & $\begin{array}{l}\text { List and define all variables for which data were sought and any } \\
\text { assumptions and simplifications made. }\end{array}$ & $2-3$ \\
\hline $\begin{array}{l}\text { Critical appraisal } \\
\text { of individual } \\
\text { sources of } \\
\text { evidence } \S\end{array}$ & 12 & $\begin{array}{l}\text { If done, provide a rationale for conducting a critical appraisal of included } \\
\text { sources of evidence; describe the methods used and how this information } \\
\text { was used in any data synthesis (if appropriate). }\end{array}$ & NA \\
\hline $\begin{array}{l}\text { Synthesis of } \\
\text { results }\end{array}$ & 13 & $\begin{array}{l}\text { Describe the methods of handling and summarizing the data that were } \\
\text { charted. }\end{array}$ & $2-3$ \\
\hline \multicolumn{4}{|l|}{ RESULTS } \\
\hline $\begin{array}{l}\text { Selection of } \\
\text { sources of } \\
\text { evidence }\end{array}$ & 14 & $\begin{array}{l}\text { Give numbers of sources of evidence screened, assessed for eligibility, and } \\
\text { included in the review, with reasons for exclusions at each stage, ideally } \\
\text { using a flow diagram. }\end{array}$ & 3 \\
\hline
\end{tabular}




\begin{tabular}{|c|c|c|c|}
\hline SECTION & ITEM & PRISMA-ScR CHECKLIST ITEM & $\begin{array}{l}\text { REPORTED } \\
\text { ON PAGE \# }\end{array}$ \\
\hline $\begin{array}{l}\text { Characteristics of } \\
\text { sources of } \\
\text { evidence }\end{array}$ & 15 & $\begin{array}{l}\text { For each source of evidence, present characteristics for which data were } \\
\text { charted and provide the citations. }\end{array}$ & $3-10$ \\
\hline $\begin{array}{l}\text { Critical appraisal } \\
\text { within sources of } \\
\text { evidence }\end{array}$ & 16 & $\begin{array}{l}\text { If done, present data on critical appraisal of included sources of evidence } \\
\text { (see item 12). }\end{array}$ & NA \\
\hline $\begin{array}{l}\text { Results of } \\
\text { individual } \\
\text { sources of } \\
\text { evidence }\end{array}$ & 17 & $\begin{array}{l}\text { For each included source of evidence, present the relevant data that were } \\
\text { charted that relate to the review questions and objectives. }\end{array}$ & $3-10$ \\
\hline $\begin{array}{l}\text { Synthesis of } \\
\text { results }\end{array}$ & 18 & $\begin{array}{l}\text { Summarize and/or present the charting results as they relate to the review } \\
\text { questions and objectives. }\end{array}$ & $3-10$ \\
\hline \multicolumn{4}{|l|}{ DISCUSSION } \\
\hline $\begin{array}{l}\text { Summary of } \\
\text { evidence }\end{array}$ & 19 & $\begin{array}{l}\text { Summarize the main results (including an overview of concepts, themes, and } \\
\text { types of evidence available), link to the review questions and objectives, and } \\
\text { consider the relevance to key groups. }\end{array}$ & $10-11$ \\
\hline Limitations & 20 & Discuss the limitations of the scoping review process. & 11 \\
\hline Conclusions & 21 & $\begin{array}{l}\text { Provide a general interpretation of the results with respect to the review } \\
\text { questions and objectives, as well as potential implications and/or next steps. }\end{array}$ & 11 \\
\hline
\end{tabular}

Funding
Describe sources of funding for the included sources of evidence, as well as sources of funding for the scoping review. Describe the role of the funders of 11 the scoping review.

JBI = Joanna Briggs Institute; PRISMA-ScR = Preferred Reporting Items for Systematic reviews and Meta-Analyses extension for Scoping Reviews. * Where sources of evidence (see second footnote) are compiled from, such as bibliographic databases, social media platforms, and Web sites. + A more inclusive/heterogeneous term used to account for the different types of evidence or data sources (e.g., quantitative and/or qualitative research, expert opinion, and policy documents) that may be eligible in a scoping review as opposed to only studies. This is not to be confused with information sources (see first footnote). $\ddagger$ The frameworks by Arksey and O'Malley (6) and Levac and colleagues $(7)$ and the JBI guidance $(4,5)$ refer to the process of data extraction in a scoping review as data charting. $§$ The process of systematically examining research evidence to assess its validity, results, and relevance before using it to inform a decision. This term is used for items 12 and 19 instead of "risk of bias" (which is more applicable to systematic reviews of interventions) to include and acknowledge the various sources of evidence that may be used in a scoping review (e.g., quantitative and/or qualitative research, expert opinion, and policy document). From: Tricco AC, Lillie E, Zarin W, O'Brien KK, Colquhoun H, Levac D, et al. PRISMA Extension for Scoping Reviews (PRISMAScR): Checklist and Explanation. Ann Intern Med. 2018;169:467-473. doi: 10.7326/M18-0850.

\section{Appendix B. Pubmed Search Strategy}

1 April 2000 to 31 December 2019; 359 records returned

1. "long term care insurance" OR "long-term care insurance" OR "care need" OR "long term care insurance certification"

2. exposure OR risk OR predict* OR relate* OR relation* OR explain* OR prevent* OR protect* OR factor* OR associat* OR correlat* OR incidence OR hazard

3. “2000/04/01"[PDat]: “2019/12/31"[PDat]

4. Humans [Mesh]

5. Japan

6. "Cohort Studies"[Mesh] OR longitudinal OR follow-up OR prospective

7. \#1 AND \#2 AND \#3 AND \#4 AND \#5 AND \#6 


\section{References}

1. National Institute on Aging, National Institutes of Health. U.S. Department of Health and Human Services Global Health and Aging: Washington, DC, USA. 2017. Available online: https://www.nia.nih.gov/sites/default/files/2017-06/global_health_ aging.pdf (accessed on 26 June 2020).

2. Johnson, R.W.; Toohey, D.; Wiener, J.M. Meeting the Future Long-Term Care Needs of the Baby Boomers: How Changing Families Will Affect Paid Helpers and Institutions. Available online: https://www.urban.org/research/publication/meeting-long-termcare-needs-baby-boomers (accessed on 22 September 2017).

3. Ministry of Internal Affairs and Communications Jinko suikei (2018 Nen 10 Gatsu 1 Nichi Genzai) [Population Estimates in October 1, 2018]. Available online: https://www.stat.go.jp/data/jinsui/2018np/index.html (accessed on 4 June 2019).

4. Tamiya, N.; Noguchi, H.; Nishi, A.; Reich, M.R.; Ikegami, N.; Hashimoto, H.; Shibuya, K.; Kawachi, I.; Campbell, J.C. Population ageing and wellbeing: Lessons from Japan's long-term care insurance policy. Lancet 2011, 378, 1183-1192. [CrossRef]

5. Meguro, K.; Tanaka, N.; Kasai, M.; Nakamura, K.; Ishikawa, H.; Nakatsuka, M.; Satoh, M.; Ouchi, Y. Prevalence of dementia and dementing diseases in the old-old population in Japan: The Kurihara Project. Implications for Long-Term Care Insurance data. Psychogeriatrics 2012, 12, 226-234. [CrossRef] [PubMed]

6. Coleman, K.; Austin, B.T.; Brach, C.; Wagner, E.H. Evidence on the Chronic Care Model in the new millennium. Health Aff. 2009, 28, 75-85. [CrossRef] [PubMed]

7. Drouin, H.; Walker, J.; McNeil, H.; Elliott, J.; Stolee, P. Measured outcomes of chronic care programs for older adults: A systematic review. BMC Geriatr. 2015, 15, 139. [CrossRef] [PubMed]

8. Tsutsui, T.; Muramatsu, N. Care-needs certification in the long-term care insurance system of Japan. J. Am. Geriatr. Soc. 2005, 53, 522-527. [CrossRef] [PubMed]

9. Ministry of Health Labour and Welfare Kaigo Hoken Jigyo Hokoku [Status Report on Long-Term Care Insurance]. Available online: https:/ / www.mhlw.go.jp/topics/kaigo/osirase/jigyo/17/dl/h29_point.pdf (accessed on 26 April 2020).

10. Ikegami, N. Financing long-term care: Lessons from Japan. Int. J. Health Policy Manag. 2019, 8, 462-466. [CrossRef] [PubMed]

11. Saito, J.; Kondo, N.; Saito, M.; Takagi, D.; Tani, Y.; Haseda, M.; Tabuchi, T.; Kondo, K. Exploring 2.5-year trajectories of functional decline in older adults by applying a growth mixture model and frequency of outings as a predictor: A 2010-2013 JAGES longitudinal study. J. Epidemiol. 2019, 29, 65-72. [CrossRef]

12. Akune, T.; Muraki, S.; Oka, H.; Tanaka, S.; Kawaguchi, H.; Tokimura, F.; Yoshida, H.; Suzuki, T.; Nakamura, K.; Yoshimura, N. Incidence of certified need of care in the long-term care insurance system and its risk factors in the elderly of Japanese population-based cohorts: The ROAD study. Geriatr. Gerontol. Int. 2014, 14, 695-701. [CrossRef] [PubMed]

13. Otsuka, H.; Kobayashi, H.; Suzuki, K.; Hayashi, Y.; Ikeda, J.; Kushimoto, M.; Omoto, W.; Hara, M.; Abe, M.; Kato, K.; et al Mobility performance among healthy older adults eligible for long-term care in Japan: A prospective observational study. Aging Clin. Exp. Res. 2020, 32, 1931-1937. [CrossRef]

14. Moriya, S.; Murata, A.; Kimura, S.; Inoue, N.; Miura, H. Predictors of eligibility for long-term care funding for older people in Japan. Australas. J. Ageing 2013, 32, 79-85. [CrossRef]

15. Makino, K.; Lee, S.; Lee, S.; Bae, S.; Jung, S.; Shinkai, Y.; Shimada, H. Daily physical activity and functional disability incidence in community-dwelling older adults with chronic pain: A prospective cohort study. Pain Med. 2019, 20, 1702-1710. [CrossRef] [PubMed]

16. Akune, T.; Muraki, S.; Oka, H.; Yoshimura, N.; Tanaka, S.; Kawaguchi, H.; Tokimura, F.; Yoshida, H.; Suzuki, T.; Nakamura, K Association of physical activities of daily living with the incidence of certified need of care in the long-term care insurance system of Japan: The ROAD study. J. Orthop. Sci. 2014, 19, 489-496. [CrossRef]

17. Fujiwara, Y.; Amano, H.; Kumagai, S.; Yoshida, H.; Fujita, K.; Naito, T.; Watanabe, N.; Nishi, M.; Mori, S.; Shinkai, S. Physical and psychological predictors for the onset of certification of long-term care insurance among older adults living independently in a community a 40-month follow-up study. Nihon Koshu Eisei Zasshi 2006, 53, 77-91. [PubMed]

18. Hirai, H.; Kondo, K.; Ojima, T.; Murata, C. Examination of risk factors for onset of certification of long-term care insurance in community-dwelling older people: AGES project 3-year follow-up study. Nihon Koshu Eisei Zasshi 2009, 56, 501-512. [PubMed]

19. Tsutsumimoto, K.; Doi, T.; Shimada, H.; Makizako, H.; Hotta, R.; Nakakubo, S.; Suzuki, T. Combined effect of slow gait speed and depressive symptoms on incident disability in older adults. J. Am. Med. Dir. Assoc. 2016, 17, 123-127. [CrossRef]

20. Hoshi, M.; Hozawa, A.; Kuriyama, S.; Nakaya, N.; Ohmori-Matsuda, K.; Sone, T.; Kakizaki, M.; Niu, K.; Fujita, K.; Ueki, S.; et al. The predictive power of physical function assessed by questionnaire and physical performance measures for subsequent disability. Aging Clin. Exp. Res. 2012, 24, 345-353.

21. Chen, S.; Honda, T.; Narazaki, K.; Chen, T.; Kishimoto, H.; Kumagai, S. Physical frailty and risk of needing long-term care in community-dwelling older adults: A 6-year prospective study in Japan. J. Nutr. Health. Aging 2019, 23, 856-861. [CrossRef]

22. Makizako, H.; Shimada, H.; Doi, T.; Tsutsumimoto, K.; Suzuki, T. Impact of physical frailty on disability in community-dwelling older adults: A prospective cohort study. BMJ Open 2015, 5, e008462. [CrossRef]

23. Shimada, H.; Makizako, H.; Doi, T.; Tsutsumimoto, K.; Suzuki, T. Incidence of disability in frail older persons with or without slow walking speed. J. Am. Med. Dir. Assoc. 2015, 16, 690-696. [CrossRef]

24. Tanaka, T.; Takahashi, K.; Akishita, M.; Tsuji, T.; Iijima, K. “Yubi-wakka” (finger-ring) test: A practical self-screening method for sarcopenia, and a predictor of disability and mortality among Japanese community-dwelling older adults. Geriatr. Gerontol. Int. 2018, 18, 224-232. [CrossRef] 
25. Moriya, S.; Tei, K.; Murata, A.; Muramatsu, M.; Inoue, N.; Miura, H. Perceived chewing ability and need for long-term care in the elderly: A 5-year follow-up study. J. Oral Rehabil. 2012, 39, 568-575. [CrossRef]

26. Matsunaga, T.; Naito, M.; Wakai, K.; Ukawa, S.; Zhao, W.; Okabayashi, S.; Ando, M.; Kawamura, T.; Tamakoshi, A. Leisure-time physical activity and risk of disability incidence: A 12-year prospective cohort study among young elderly of the same age at baseline. J. Epidemiol. 2017, 27, 538-545. [CrossRef]

27. Tomata, Y.; Zhang, S.; Sugiyama, K.; Kaiho, Y.; Sugawara, Y.; Tsuji, I. Changes in time spent walking and the risk of incident dementia in older Japanese people: The Ohsaki Cohort 2006 Study. Age Ageing 2017, 46, 857-860. [CrossRef] [PubMed]

28. Tomata, Y.; Zhang, S.; Sugawara, Y.; Tsuji, I. Impact of time spent walking on incident dementia in elderly Japanese. Int. J. Geriatr. Psychiatry 2019, 34, 204-209. [CrossRef] [PubMed]

29. Makino, K.; Makizako, H.; Doi, T.; Tsutsumimoto, K.; Hotta, R.; Nakakubo, S.; Suzuki, T.; Shimada, H. Impact of fear of falling and fall history on disability incidence among older adults: Prospective cohort study. Int. J. Geriatr. Psychiatry 2018, 33, 658-662. [CrossRef] [PubMed]

30. Ikeda, A.; Yamagishi, K.; Tanigawa, T.; Cui, R.; Yao, M.; Noda, H.; Umesawa, M.; Chei, C.; Yokota, K.; Shiina, Y.; et al. Cigarette smoking and risk of disabling dementia in a Japanese rural community: A nested case-control study. Cerebrovasc. Dis. 2008, 25, 324-331. [CrossRef]

31. Noguchi-Shinohara, M.; Hirako, K.; Fujiu, M.; Sagae, M.; Samuta, H.; Nakamura, H.; Yamada, M. Presence of a synergistic interaction between current cigarette smoking and diabetes mellitus on development of dementia in older adults. J. Alzheimers Dis. 2019, 71, 833-840. [CrossRef]

32. Tomata, Y.; Kakizaki, M.; Nakaya, N.; Tsuboya, T.; Sone, T.; Kuriyama, S.; Hozawa, A.; Tsuji, I. Green tea consumption and the risk of incident functional disability in elderly Japanese: The Ohsaki Cohort 2006 Study. Am. J. Clin. Nutr. 2012, 95, 732-739. [CrossRef]

33. Matsuyama, S.; Zhang, S.; Tomata, Y.; Abe, S.; Tanji, F.; Sugawara, Y.; Tsuji, I. Association between improved adherence to the Japanese diet and incident functional disability in older people: The Ohsaki Cohort 2006 Study. Clin. Nutr. 2020, 39, 2238-2245. [CrossRef]

34. Tomata, Y.; Watanabe, T.; Sugawara, Y.; Chou, W.-T.; Kakizaki, M.; Tsuji, I. Dietary patterns and incident functional disability in elderly Japanese: The Ohsaki Cohort 2006 Study. J. Gerontol. Ser. A 2014, 69, 843-851. [CrossRef]

35. Sugiyama, K.; Tomata, Y.; Kaiho, Y.; Honkura, K.; Sugawara, Y.; Tsuji, I. Association between coffee consumption and incident risk of disabling dementia in elderly Japanese: The Ohsaki Cohort 2006 Study. J. Alzheimer's Dis. 2016, 50, 491-500. [CrossRef] [PubMed]

36. Tomata, Y.; Sugiyama, K.; Kaiho, Y.; Honkura, K.; Watanabe, T.; Zhang, S.; Sugawara, Y.; Tsuji, I. Green tea consumption and the risk of incident dementia in elderly Japanese: The Ohsaki Cohort 2006 Study. Am. J. Geriatr. Psychiatry 2016, 24, 881-889. [CrossRef] [PubMed]

37. Tomata, Y.; Sugiyama, K.; Kaiho, Y.; Honkura, K.; Watanabe, T.; Zhang, S.; Sugawara, Y.; Tsuji, I. Dietary patterns and incident dementia in elderly Japanese: The Ohsaki Cohort 2006 Study. J. Gerontol. Ser. A 2016, 71, 1322-1328. [CrossRef]

38. Zhang, S.; Tomata, Y.; Sugiyama, K.; Sugawara, Y.; Tsuji, I. Citrus consumption and incident dementia in elderly Japanese: The Ohsaki Cohort 2006 Study. Br. J. Nutr. 2017, 117, 1174-1180. [CrossRef] [PubMed]

39. Zhang, S.; Tomata, Y.; Sugiyama, K.; Sugawara, Y.; Tsuji, I. Mushroom consumption and incident dementia in elderly Japanese: The Ohsaki Cohort 2006 Study. J. Am. Geriatr. Soc. 2017, 65, 1462-1469. [CrossRef]

40. Lu, Y.; Sugawara, Y.; Zhang, S.; Tomata, Y.; Tsuji, I. Changes in sleep duration and the risk of incident dementia in the elderly Japanese: The Ohsaki Cohort 2006 Study. Sleep 2018, 41. [CrossRef]

41. Zhang, L.; Ukawa, S.; Zhao, W.; Okabayashi, S.; Ando, M.; Wakai, K.; Tsushita, K.; Kawamura, T.; Tamakoshi, A. Daily sleep duration and the risk of incident disability among younger elderly Japanese adults in the New Integrated Suburban Seniority Investigation Project: A prospective study using competing event analysis. Geriatr. Gerontol. Int. 2019, 19, 945-949. [CrossRef]

42. Zhang, S.; Tomata, Y.; Newson, R.B.; Sugawara, Y.; Tsuji, I. Combined healthy lifestyle behaviours and incident disability in an elderly population: The Ohsaki Cohort 2006 Study. J. Epidemiol. Community Health 2018, 72, 679-684. [CrossRef]

43. Zhang, S.; Tomata, Y.; Discacciati, A.; Otsuka, T.; Sugawara, Y.; Tanji, F.; Tsuji, I. Combined healthy lifestyle behaviors and disability-free survival: The Ohsaki Cohort 2006 Study. J. Gen. Intern. Med. 2019, 34, 1724-1729. [CrossRef]

44. Yagi, A.; Hayasaka, S.; Ojima, T.; Sasaki, Y.; Tsuji, T.; Miyaguni, Y.; Nagamine, Y.; Namiki, T.; Kondo, K. Bathing frequency and onset of functional disability among Japanese older adults: A prospective 3-year cohort study from the JAGES. J. Epidemiol. 2019, 29, 451-456. [CrossRef]

45. Aida, J.; Kondo, K.; Hirai, H.; Nakade, M.; Yamamoto, T.; Hanibuchi, T.; Osaka, K.; Sheiham, A.; Tsakos, G.; Watt, R.G. Association between dental status and incident disability in an older Japanese population. J. Am. Geriatr. Soc. 2012, 60, 338-343. [CrossRef] [PubMed]

46. Komiyama, T.; Ohi, T.; Miyoshi, Y.; Tsuboi, A.; Hattori, Y.; Tomata, Y.; Kakizaki, M.; Tsuji, I.; Watanabe, M. Relationship between regular dentist and long-term care insurance certification in community-dwelling elderly population: A cohort study of the Tsurugaya Project. Ronen Shika Igaku 2014, 28, 337-344.

47. Komiyama, T.; Ohi, T.; Miyoshi, Y.; Murakami, T.; Tsuboi, A.; Tomata, Y.; Tsuji, I.; Watanabe, M.; Hattori, Y. Association between tooth loss, receipt of dental care, and functional disability in an elderly Japanese population: The Tsurugaya Project. J. Am. Geriatr. Soc. 2016, 64, 2495-2502. [CrossRef] [PubMed] 
48. Komiyama, T.; Ohi, T.; Miyoshi, Y.; Murakami, T.; Tsuboi, A.; Tomata, Y.; Tsuji, I.; Watanabe, M.; Hattori, Y. Relationship between status of dentition and incident functional disability in an elderly Japanese population: Prospective cohort study of the Tsurugaya Project. J. Prosthodont. Res. 2018, 62, 443-448. [CrossRef]

49. Ohi, T.; Komiyama, T.; Miyoshi, Y.; Murakami, T.; Tsuboi, A.; Tomata, Y.; Tsuji, I.; Watanabe, M.; Hattori, Y. Maximum occlusal force and incident functional disability in older adults: The Tsurugaya Project. JDR Clin. Trans. Res. 2018, 3, 195-202. [CrossRef]

50. Bando, S.; Tomata, Y.; Aida, J.; Sugiyama, K.; Sugawara, Y.; Tsuji, I. Impact of oral self-care on incident functional disability in elderly Japanese: The Ohsaki Cohort 2006 Study. BMJ Open 2017, 7, e017946. [CrossRef]

51. Yamamoto, T.; Kondo, K.; Hirai, H.; Nakade, M.; Aida, J.; Hirata, Y. Association between self-reported dental health status and onset of dementia: A 4-year prospective cohort study of older Japanese adults from the Aichi Gerontological Evaluation Study (AGES) Project. Psychosom. Med. 2012, 74, 241-248. [CrossRef]

52. Nitta, A.; Hozawa, A.; Kuriyama, S.; Nakaya, N.; Ohmori-Matsuda, K.; Sone, T.; Kakizaki, M.; Ebihara, S.; Ichiki, M.; Arai, H.; et al. Relationship between peripheral arterial disease and incident disability among elderly Japanese: The Tsurugaya Project. J. Atheroscler. Thromb. 2010, 17, 1290-1296. [CrossRef]

53. Jinnouchi, H.; Kitamura, A.; Yamagishi, K.; Kiyama, M.; Imano, H.; Okada, T.; Cui, R.; Umesawa, M.; Muraki, I.; Hayama-Terada, M.; et al Retinal vascular changes and prospective risk of disabling dementia: The Circulatory Risk in Communities Study (CIRCS). J. Atheroscler. Thromb. 2017, 24, 687-695. [CrossRef]

54. Yamada, M.; Arai, H.; Nishiguchi, S.; Kajiwara, Y.; Yoshimura, K.; Sonoda, T.; Yukutake, T.; Kayama, H.; Tanigawa, T.; Aoyama, T. Chronic kidney disease (CKD) is an independent risk factor for long-term care insurance (LTCI) need certification among older Japanese adults: A two-year prospective cohort study. Arch. Gerontol. Geriatr. 2013, 57, 328-332. [CrossRef]

55. Lee, S.; Lee, S.; Bae, S.; Harada, K.; Jung, S.; Makino, K.; Shimada, H. Impact of sedentary time on chronic kidney disease and disability incidence in community-dwelling Japanese older adults: A 4-year prospective cohort study. J. Aging Phys. Act. 2019, 27, 184-190. [CrossRef] [PubMed]

56. Himeno, T.; Okuno, T.; Watanabe, K.; Nakajima, K.; Iritani, O.; Yano, H.; Morita, T.; Igarashi, Y.; Okuro, M.; Morimoto, S. Range in systolic blood pressure and care-needs certification in long-term care insurance in community-dwelling older patients with chronic kidney disease. J. Int. Med. Res. 2018, 46, 293-306. [CrossRef] [PubMed]

57. Watanabe, K.; Okuro, M.; Okuno, T.; Iritani, O.; Yano, H.; Himeno, T.; Morita, T.; Igarashi, Y.; Nakahashi, T.; Morimoto, S. Comorbidity of chronic kidney disease, diabetes and lower glycated hemoglobin predicts support/care-need certification in community-dwelling older adults. Geriatr. Gerontol. Int. 2018, 18, 521-529. [CrossRef] [PubMed]

58. Nishiguchi, S.; Yamada, M.; Sonoda, T.; Kayama, H.; Tanigawa, T.; Yukutake, T.; Aoyama, T. Cognitive decline predicts long-term care insurance requirement certification in community-dwelling older Japanese adults: A prospective cohort study. Dement. Geriatr. Cogn. Dis. Extra 2013, 3, 312-319. [CrossRef] [PubMed]

59. Taniguchi, Y.; Fujiwara, Y.; Shinozaki, T.; Amano, H.; Nishi, M.; Murayama, H.; Nofuji, Y.; Seino, S.; Narita, M.; Matsuo, E.; et al. Prospective study of cognitive decline assessed using the mini-mental state examination and the risk of incident long-term care insurance among community-dwelling older Japanese. Nihon Ronen Igakkai Zasshi 2015, 52, 86-93. [CrossRef] [PubMed]

60. Shimada, H.; Lee, S.; Doi, T.; Bae, S.; Tsutsumimoto, K.; Arai, H. Prevalence of psychological frailty in Japan: NCGG-SGS as a Japanese National Cohort Study. J. Clin. Med. 2019, 8, 1554. [CrossRef]

61. Tomata, Y.; Watanabe, T.; Tanji, F.; Zhang, S.; Sugawara, Y.; Tsuji, I. The impact of psychological distress on incident functional disability in elderly Japanese: The Ohsaki Cohort 2006 Study. Int. J. Environ. Res. Public Health 2018, 15, 2502. [CrossRef]

62. Yamazaki, S.; Nakano, K.; Saito, E.; Yasumura, S. Prediction of functional disability by depressive state among communitydwelling elderly in Japan: A prospective cohort study. Geriatr. Gerontol. Int. 2012, 12, 680-687. [CrossRef]

63. Ohmori-Matsuda, K.; Hozawa, A.; Sone, T.; Koizumi-Masamune, Y.; Nakaya, N.; Kuriyama, S.; Suzuki, S.; Awata, S.; Tsuji, I. Depression and the risk of long-term care insurance certification: The Tsurugaya Project. Nihon Koshu Eisei Zasshi 2010, 57, 538-549.

64. Bae, S.; Lee, S.; Lee, S.; Harada, K.; Makizako, H.; Park, H.; Shimada, H. Combined effect of self-reported hearing problems and level of social activities on the risk of disability in Japanese older adults: A population-based longitudinal study. Maturitas 2018, 115, 51-55. [CrossRef]

65. Makino, K.; Lee, S.; Bae, S.; Jung, S.; Shinkai, Y.; Chiba, I.; Shimada, H. Pain characteristics and incidence of functional disability among community-dwelling older adults. PLoS ONE 2019, 14, e0215467. [CrossRef]

66. Higashiguchi, M.; Nakaya, N.; Ohmori, K.; Shimazu, T.; Sone, T.; Hozawa, A.; Kuriyama, S.; Tsuji, I. Malnutrition and the risk of long-term care insurance certification or mortality. A cohort study of the Tsurugaya Project. Nihon Koshu Eisei Zasshi 2008, 55, 433-439.

67. Hozawa, A.; Sugawara, Y.; Tomata, Y.; Kakizaki, M.; Ohmori-Matsuda, K.; Nakaya, N.; Kuriyama, S.; Fukao, A.; Tsuji, I. Relationships between N-terminal pro B-type natriuretic peptide and incident disability and mortality in older communitydwelling adults: The Tsurugaya Study. J. Am. Geriatr. Soc. 2010, 58, 2439-2441. [CrossRef] [PubMed]

68. Hozawa, A.; Sugawara, Y.; Tomata, Y.; Kakizaki, M.; Tsuboya, T.; Ohmori-Matsuda, K.; Nakaya, N.; Kuriyama, S.; Fukao, A.; Tsuji, I. Relationship between serum adiponectin levels and disability-free survival among community-dwelling elderly individuals: The Tsurugaya Project. J. Gerontol. Ser. A 2012, 67A, 530-536. [CrossRef] [PubMed] 
69. Hozawa, A.; Sugawara, Y.; Tomata, Y.; Kakizaki, M.; Tsuboya, T.; Ohmori-Matsuda, K.; Nakaya, N.; Kuriyama, S.; Fukao, A.; Tsuji, I. Relationship between serum isoflavone levels and disability-free survival among community-dwelling elderly individuals: Nested case-control study of the Tsurugaya Project. J. Gerontol. Ser. A 2013, 68, 465-472. [CrossRef] [PubMed]

70. Hoshi, R.; Tomata, Y.; Kakizaki, M.; Tsuboya, T.; Nagai, M.; Watanabe, I.; Hozawa, A.; Tsuji, I. Serum total cholesterol levels and eligibility for long-term care insurance: A prospective cohort study of the Tsurugaya Project. Nihon Koshu Eisei Zasshi 2013, 60, 435-443.

71. Yamagishi, K.; Ikeda, A.; Moriyama, Y.; Chei, C.L.; Noda, H.; Umesawa, M.; Cui, R.; Nagao, M.; Kitamura, A.; Yamamoto, Y.; et al. Serum coenzyme Q10 and risk of disabling dementia: The Circulatory Risk in Communities Study (CIRCS). Atherosclerosis 2014, 237, 400-403. [CrossRef]

72. Chei, C.L.; Yamagishi, K.; Ikeda, A.; Noda, H.; Maruyama, M.; Cui, R.; Imano, H.; Kiyama, M.; Kitamura, A.; Asada, T.; et al. $\mathrm{C}$-reactive protein levels and risk of disabling dementia with and without stroke in Japanese: The Circulatory Risk in Communities Study (CIRCS). Atherosclerosis 2014, 236, 438-443. [CrossRef]

73. Yamagishi, K.; Ikeda, A.; Chei, C.L.; Noda, H.; Umesawa, M.; Cui, R.; Muraki, I.; Ohira, T.; Imano, H.; Sankai, T.; et al. Serum $\alpha$-linolenic and other $\omega-3$ fatty acids, and risk of disabling dementia: Community-based nested case-control study. Clin. Nutr. 2017, 36, 793-797. [CrossRef]

74. Doi, T.; Shimada, H.; Makizako, H.; Tsutsumimoto, K.; Hotta, R.; Nakakubo, S.; Suzuki, T. Insulin-Like Growth Factor-1 Related to Disability Among Older Adults. J. Gerontol. Ser. A 2016, 71, 797-802. [CrossRef]

75. Yamazaki, H.; Kamitani, T.; Matsui, T.; Yamamoto, Y.; Fukuhara, S. Association of low alanine aminotransferase with loss of independence or death: A 5-year population-based cohort study. J. Gastroenterol. Hepatol. 2019, 34, 1793-1799. [CrossRef]

76. Takahashi, S.; Tanaka, F.; Yonekura, Y.; Tanno, K.; Ohsawa, M.; Sakata, K.; Koshiyama, M.; Okayama, A.; Nakamura, M. The urine albumin-creatinine ratio is a predictor for incident long-term care in a general population. PLoS ONE 2018, 13, e0195013. [CrossRef] [PubMed]

77. Okuno, T.; Watanabe, K.; Nakajima, K.; Iritani, O.; Yano, H.; Morita, T.; Himeno, T.; Igarashi, Y.; Okuro, M.; Morimoto, S. Major electrocardiographic abnormality predicts support/care-need certification and/or death in community-dwelling older adults with no history of cardiovascular disease. Geriatr. Gerontol. Int. 2017, 17, 1967-1976. [CrossRef] [PubMed]

78. Honda, A.; Tanabe, N.; Seki, N.; Ogawa, Y.; Suzuki, H. Underweight/overweight and the risk of long-term care: Follow-up study using data of the Japanese long-term care insurance system. Geriatr. Gerontol. Int. 2014, 14, 328-335. [CrossRef] [PubMed]

79. Zhang, S.; Tomata, Y.; Sugiyama, K.; Kaiho, Y.; Honkura, K.; Watanabe, T.; Tanji, F.; Sugawara, Y.; Tsuji, I. Body mass index and the risk of incident functional disability in elderly Japanese: The Ohsaki Cohort 2006 Study. Medicine 2016, 95, e4452. [CrossRef]

80. Zhang, S.; Tomata, Y.; Tanji, F.; Sugawara, Y.; Tsuji, I. The relationship between body mass index and disability-free survival in elderly Japanese: The Ohsaki Cohort 2006 Study. Int. J. Obes. 2019, 43, 2254-2263. [CrossRef]

81. Ashida, T.; Kondo, N.; Kondo, K. Social participation and the onset of functional disability by socioeconomic status and activity type: The JAGES cohort study. Prev. Med. 2016, 89, 121-128. [CrossRef]

82. Otsuka, T.; Tomata, Y.; Zhang, S.; Sugiyama, K.; Tanji, F.; Sugawara, Y.; Tsuji, I. Association between social participation and incident risk of functional disability in elderly Japanese: The Ohsaki Cohort 2006. J. Psychosom. Res. 2018, 111, 36-41. [CrossRef]

83. Nemoto, Y.; Saito, T.; Kanamori, S.; Tsuji, T.; Shirai, K.; Kikuchi, H.; Maruo, K.; Arao, T.; Kondo, K. An additive effect of leading role in the organization between social participation and dementia onset among Japanese older adults: The AGES cohort study. BMC Geriatr. 2017, 17, 297. [CrossRef]

84. Saito, T.; Murata, C.; Saito, M.; Takeda, T.; Kondo, K. Influence of social relationship domains and their combinations on incident dementia: A prospective cohort study. J. Epidemiol. Commun. Health 2018, 72, 7-12. [CrossRef]

85. Yokokawa, H.; Yasumura, S.; Tanno, K.; Ohsawa, M.; Onoda, T.; Itai, K.; Kawamura, K.; Sakata, K. Association between homebound status and newly certified need of care among elderly in a rural community: The Iwate-Kenpoku cohort (IwateKENCO) study. Nihon Ronen Igakkai Zasshi 2009, 46, 447-457. [CrossRef] [PubMed]

86. Makizako, H.; Shimada, H.; Tsutsumimoto, K.; Lee, S.; Doi, T.; Nakakubo, S.; Hotta, R.; Suzuki, T. Social frailty in communitydwelling older adults as a risk factor for disability. J. Am. Med. Dir. Assoc. 2015, 16, 1003.E7-1003.E11. [CrossRef] [PubMed]

87. Noguchi, T.; Kondo, K.; Saito, M.; Nakagawa-Senda, H.; Suzuki, S. Community social capital and the onset of functional disability among older adults in Japan: A multilevel longitudinal study using Japan Gerontological Evaluation Study (JAGES) data. BMJ Open 2019, 9, e029279. [CrossRef]

88. Saito, E.; Ueki, S.; Yasuda, N.; Yamazaki, S.; Yasumura, S. Risk factors of functional disability among community-dwelling elderly people by household in Japan: A prospective cohort study. BMC Geriatr. 2014, 14, 93. [CrossRef] [PubMed]

89. Saito, T.; Murata, C.; Aida, J.; Kondo, K. Cohort study on living arrangements of older men and women and risk for basic activities of daily living disability: Findings from the AGES project. BMC Geriatr. 2017, 17, 183. [CrossRef]

90. Momosaki, R.; Wakabayashi, H.; Maeda, K.; Shamoto, H.; Nishioka, S.; Kojima, K.; Tani, Y.; Suzuki, N.; Hanazato, M.; Kondo, K. Association between food store availability and the Incidence of functional disability among community-dwelling older adults: Results from the Japanese Gerontological Evaluation Cohort Study. Nutrients 2019, 11, 2369. [CrossRef]

91. Tani, Y.; Suzuki, N.; Fujiwara, T.; Hanazato, M.; Kondo, K. Neighborhood food environment and dementia incidence: The Japan Gerontological Evaluation Study Cohort Survey. Am. J. Prev. Med. 2019, 56, 383-392. [CrossRef] 
92. Takasugi, T.; Tsuji, T.; Nagamine, Y.; Miyaguni, Y.; Kondo, K. Socio-economic status and dementia onset among older Japanese: A 6-year prospective cohort study from the Japan Gerontological Evaluation Study. Int. J. Geriatr. Psychiatry 2019, 34, 1642-1650. [CrossRef]

93. Nurrika, D.; Zhang, S.; Tomata, Y.; Sugawara, Y.; Tanji, F.; Tsuji, I. Education level and incident functional disability in elderly Japanese: The Ohsaki Cohort 2006 study. PLoS ONE 2019, 14, e0213386. [CrossRef]

94. Kondo, N.; Kawachi, I.; Hirai, H.; Kondo, K.; Subramanian, S.V.; Hanibuchi, T.; Yamagata, Z. Relative deprivation and incident functional disability among older Japanese women and men: Prospective cohort study. J. Epidemiol. Commun. Health 2009, 63, 461-467. [CrossRef]

95. Kondo, N.; Suzuki, K.; Minai, J.; Yamagata, Z. Positive and negative effects of finance-based social capital on incident functional disability and mortality: An 8-year prospective study of elderly Japanese. J. Epidemiol. 2012, 22, 543-550. [CrossRef]

96. Tomata, Y.; Hozawa, A.; Ohmori-Matsuda, K.; Nagai, M.; Sugawara, Y.; Nitta, A.; Kuriyama, S.; Tsuji, I. Validation of the Kihon Checklist for predicting the risk of 1-year incident long-term care insurance certification: The Ohsaki Cohort 2006 Study. Nihon Koshu Eisei Zasshi 2011, 58, 3-13. [PubMed]

97. Kamegaya, T.; Yamaguchi, H.; Hayashi, K. Evaluation by the Basic Checklist and the risk of 3 years incident long-term care insurance certification. J. Gen. Fam. Med. 2017, 18, 230-236. [CrossRef] [PubMed]

98. Okabe, D.; Tsuji, T.; Kondo, K. The Comprehensive Geriatric Assessment predicts healthy life expectancy better than health checkups in older people: JAGES cohort study. Nihon Ronen Igakkai Zasshi 2018, 55, 367-377. [CrossRef]

99. Satake, S.; Shimokata, H.; Senda, K.; Kondo, I.; Toba, K. Validity of total Kihon Checklist Score for predicting the incidence of 3-year dependency and mortality in a community-dwelling older population. J. Am. Med. Dir. Assoc. 2017, 18, 552.E1-552.E6. [CrossRef]

100. Katsura, T.; Fujimoto, M.; Shizawa, M.; Hoshino, A.; Usui, K.; Yokoyama, E.; Hara, M. A retrospective cohort study on the risk assessment of newly certificated long-term care need of elderly individuals in a community: Basic checklist and specific health checkup. J. Rural. Med. 2017, 12, 68-84. [CrossRef] [PubMed]

101. Shinkai, S.; Watanabe, N.; Yoshida, H.; Fujiwara, Y.; Amano, H.; Lee, S.; Nishi, M.; Tsuchiya, Y. Research on screening for frailty: Development of "the Kaigo-Yobo Checklist". Nihon Koshu Eisei Zasshi 2010, 57, 345-354. [PubMed]

102. Kotaki, Y.; Tomata, Y.; Tanji, F.; Zhang, S.; Sugawara, Y.; Tsuji, I. Joint impact of seven risk factors on incident dementia in elderly Japanese: The Ohsaki Cohort 2006 Study. J. Neurol. 2019, 266, 1222-1229. [CrossRef] [PubMed]

103. Arai, Y.; Zarit, S.H.; Kumamoto, K.; Takeda, A. Are there inequities in the assessment of dementia under Japan's LTC insurance system? Int. J. Geriatr. Psychiatry 2003, 18, 346-352. [CrossRef]

104. Noda, H.; Yamagishi, K.; Ikeda, A.; Asada, T.; Iso, H. Identification of dementia using standard clinical assessments by primary care physicians in Japan. Geriatr. Gerontol. Int. 2018, 18, 738-744. [CrossRef]

105. Ohara, T.; Ninomiya, T.; Hata, J.; Ozawa, M.; Yoshida, D.; Mukai, N.; Nagata, M.; Iwaki, T.; Kitazono, T.; Kanba, S.; et al. Midlife and Late-Life Smoking and Risk of Dementia in the Community: The Hisayama Study. J. Am. Geriatr. Soc. 2015, 63, 2332-2339. [CrossRef]

106. Takashima, N.; Miura, K.; Hozawa, A.; Okamura, T.; Hayakawa, T.; Okuda, N.; Kadowaki, T.; Murakami, Y.; Kita, Y.; Nakamura, Y.; et al. Cigarette smoking in middle age and a long-term risk of impaired activities of daily living: NIPPON DATA80. Nicotine Tob. Res. 2010, 12, 944-949. [CrossRef] [PubMed]

107. Nakamura, Y.; Hozawa, A.; Turin, T.C.; Takashima, N.; Okamura, T.; Hayakawa, T.; Kita, Y.; Okayama, A.; Miura, K.; Ueshima, H.; et al. Dietary habits in middle age and future changes in activities of daily living-NIPPON DATA80. Gerontology 2009, 55, 707-713. [CrossRef] [PubMed]

108. Kojima, M.; Satake, S.; Osawa, A.; Arai, H. Management of frailty under COVID-19 pandemic in Japan. Glob. Health Med. 2021, 3 , 196-202. [CrossRef] [PubMed] 